\title{
Overexpression of ING3 is associated with attenuation of migration and invasion in breast cancer
}

\author{
HUIMENG LI $^{1 *}$, HENGYU ZHANG $^{1 *}$, XIN TAN $^{1 *}$, DEQUAN LIU $^{1}$, RONG GUO $^{1}$, \\ MAOHUA WANG ${ }^{1}$, YIYIN TANG ${ }^{1}$, KAI ZHENG ${ }^{1}$, WENLIN CHEN ${ }^{1}$, HONGWAN LI $^{1}$, \\ MINGJIAN TAN ${ }^{1}, \mathrm{KE} \mathrm{WANG}^{1}$, RUI LIU ${ }^{2}$ and SHICONG TANG ${ }^{1}$ \\ ${ }^{1}$ Department of Breast Surgery, The Third Affiliated Hospital of Kunming Medical University, \\ Yunnan Cancer Hospital, Kunming, Yunnan 650118; ${ }^{2}$ Department of Clinical Laboratory, \\ The Second Affiliated Hospital of Kunming Medical University, Kunming, Yunnan 650101, P.R. China
}

Received May 9, 2020; Accepted March 24, 2021

DOI: $10.3892 /$ etm.2021.10131

\begin{abstract}
Inhibitor of growth 3 (ING3) has been identified as a potential cancer drug target, but little is known about its role in breast cancer. Thus, the present study aimed to investigate ING3 expression in breast cancer, its clinical value, and how ING3 influences the migration and invasion of breast cancer cells. The Cancer Genome Atlas and UALCAN databases were used to analyze ING3 expression in cancer tissues and normal tissues. Survival analysis was performed using the UALCAN, UCSC Xena and KM-plot databases. In addition, reverse transcription-quantitative $\mathrm{PCR}$ and western blot analyses were performed to detect ING3 mRNA and protein expression levels. ING3 was overexpressed via lentiviral vector transfection, while the Transwell and wound healing assays were performed to assess the cell migratory and invasive abilities. Protein interaction and pathway analyses were performed using the GeneMANIA and Kyoto Encyclopedia of Genes and Genomes databases, respectively. The results demonstrated that ING3 expression was significantly lower in cancer tissues compared with normal tissues $(\mathrm{P}<0.05)$. In addition, luminal $\mathrm{A}$ and human epidermal growth factor receptor 2 (HER2)-enriched breast cancer tissues expressed lower levels of ING3 compared with normal breast tissues.
\end{abstract}

Correspondence to: Dr Rui Liu, Department of Clinical Laboratory, The Second Affiliated Hospital of Kunming Medical University, 374 Dianmian Road, Kunming, Yunnan 650101, P.R. China

E-mail: 782738758@qq.com

Dr Shicong Tang, Department of Breast Surgery, The Third Affiliated Hospital of Kunming Medical University, Yunnan Cancer Hospital, 519 Kunzhou Road, Xishan, Kunming, Yunnan 650118, P.R. China

E-mail: tang_shicong@126.com

${ }^{*}$ Contributed equally

Key words: inhibitor of growth 3, breast cancer, migration, invasion
Notably, statistically significant differences were observed in long-term survival between patients with luminal A $(\mathrm{P}=0.04)$ and HER2-enriched $(\mathrm{P}=0.008)$ breast cancer, with high and low expression levels of ING3. The results of the Transwell migration and invasion assays demonstrated that overexpression of ING3 significantly inhibited the migratory and invasive abilities of MCF7 $(\mathrm{P}<0.05)$ and HCC1937 $(\mathrm{P}<0.05)$ cells. The results of the wound healing assay demonstrated that the percentage wound closure significantly decreased in cells transfected with LV5-ING3 compared with the negative control group at $12 \mathrm{~h}(\mathrm{P}<0.05)$ and $24 \mathrm{~h}(\mathrm{P}<0.01)$. The PI3K/AKT, JAK/STAT, NF- $\kappa \mathrm{B}$ and Wnt/ $\beta$-catenin pathways are the potential pathways regulated by ING3. Notably, overexpression of ING3 inhibited migration and invasion in vitro. However, further studies are required to determine whether ING3 regulates the biological behavior of breast cancer via tumor-related pathways.

\section{Introduction}

Breast cancer is the most common malignant tumor in women worldwide; the incidence rate increases by $0.3 \%$ per year and it has been estimated that there will be 2.3 million new cases of breast cancer in 2020 and breast cancer has surpassed lung cancer in the number of new cases (1-3). Recurrence and metastasis following systematic therapy are the most common causes of mortality (4). Thus, it is important to identify novel therapeutic targets for breast cancer.

Inhibitor of growth 3 (ING3) is a member of the ING family (5), which consists of five members with different subtypes, according to alternative splicing (6). Their encoded proteins comprise a highly conserved plant homeodomain, a Cys4-His-Cys3 form of zinc finger that directly interacts with histone $\mathrm{H} 3$, and a nuclear localization sequence $(6,7)$. ING proteins play significant roles in several biological processes, including apoptosis, DNA repair, cell cycle regulation and histone methylation $(8,9)$. Recent studies have reported that the ING family are closely associated with cancer $(10,11)$. ING family members are tumor suppressors that decrease invasion, migration and proliferation of different types of cancer (12-14). 
ING3 is in 7q31 of chromosome seven, and is considered a suppressor in different types of cancer $(10,15)$. Li et al (16) suggested that downregulation of ING3 expression promotes the proliferation of head and neck squamous cell carcinoma cells. Furthermore, Lu et al (17) demonstrated that downregulation of ING3 expression promotes tumorigenesis in hepatocellular carcinoma. However, ING3 has been reported to act as an oncogene in prostate cancer, which promotes cell proliferation $(18,19)$. In melanoma, ING3 nuclear expression is downregulated and associated with low disease-specific 5-year survival rates (20), and the nuclear localization sequence of ING3 is critical to its function as a tumor suppressor (21). However, the role of ING3 in breast cancer remains unknown. Previous studies have demonstrated that ING3 is frequently expressed in breast cancer and gynecological cancers; however, ING3 expression has not been detected in the nucleus of breast cancer tissues $(7,22)$.

In most cases, ING3 is considered a tumor suppressor $(16,17,23)$, thus it was hypothesized that ING3 does not play an inhibitory role in breast cancer due to loss of nuclear localization capacity.

To further investigate the effect of ING3 on the biological behavior of breast cancer, ING3 expression was analyzed in breast cancer tissues and normal tissues to determine its influence on the prognosis of patients with breast cancer. The role of ING3 on the migration and invasion of breast cancer cells was also investigated.

\section{Materials and methods}

Patients, tissue samples and follow-up. The present study was approved by the Ethics Committees of the Third Affiliated Hospital of Kunming Medical University, Yunnan Cancer Hospital (Kunming, China; approval no. QT202002), and written informed consent was provided by all patients prior to the study start. The UALCAN database (http://ualcan.path. uab.edu) was used to analyze ING3 expression in cancer tissues and normal tissues. Follow-up and survival analyses were performed using the UALCAN and KM-plot (http://kmplot. com/analysis) databases. Patient data and ING3 expression data (FPKM) were downloaded from The Cancer Genome Atlas (TCGA) (https://portal.gdc.cancer.gov) (TCGA-BRCA) and UCSC Xena (http://xena.ucsc.edu/public) databases (TCGA.BRCA.sampleMap/BRCA_clinicalMatrix). R (4.0.2) (24) software and Perl (5.28.1; https://www.activestate. com/products/perl/downloads) software were to determine whether the long-term survival of patients with different clinical tumor-node-metastasis (TNM) stages (25) and subtypes (PAM50) were associated with ING3 expression levels. Median ING3 expression levels between each subgroup was used to distinguish between the high and low expression groups, as follows: Stage I, 2.02357250; stage II, 1.9492; stage III, 1.894254; stage IV, 1.794536; luminal A, 1.803995; luminal B, 1.824826, human epidermal growth factor receptor 2 (HER2)-enriched, 1.497432; basal-like, 2.346218.

Primary cell separation. Normal breast epithelial cells (NBECs) were separated from tissue samples following surgical resection. Tissues were transported on ice in RPMI-1640 medium (Corning, Inc.) supplemented with
$1 \%$ penicillin/streptomycin (Biological Industries), and used to isolate primary cells within $2 \mathrm{~h}$. The tissues were washed three times with DPBS (Beijing Solarbio Science \& Technology Co., Ltd.) and trimmed of excess fat, prior to cutting into 1-2 mm thick sections on ice. Type I collagenase (1.5 mg/ml, Sigma-Aldrich; Merck KGaA) was dissolved in DPBS containing 5\% fetal bovine serum (FBS; Corning, Inc.) to digest tissues into cells. Tissues were dissociated by manual agitation for $20-40 \mathrm{~min}$ at $37^{\circ} \mathrm{C}$, and digestion was observed under a light microscope (magnification, x100). Cells were washed three times with DPBS containing 0.04\% FBS to stop digestion and collected via centrifugation at $4^{\circ} \mathrm{C} 3,000 \mathrm{xg}$ for $5 \mathrm{~min}$. Red Blood Cell lysis buffer (Invitrogen; Thermo Fisher Scientific, Inc.) was used to lyse erythrocytes on ice. Cells were re-washed three times with DPBS and cultured in RPMI-1640 medium supplemented with 10\% FBS (Corning, Inc.), at $37^{\circ} \mathrm{C}$ with $95 \%$ air and $5 \% \mathrm{CO}_{2}$.

Cell lines and culture. Human breast cancer cell lines, HCC1937 and MCF7, were purchased from the Cell Bank of Type Culture Collection of the Chinese Academy of Sciences. Cells were maintained in RPMI-1640 medium supplemented with $10 \%$ FBS (both purchased from Corning, Inc.), at $37^{\circ} \mathrm{C}$ with $95 \%$ air and $5 \% \mathrm{CO}_{2}$.

Lentiviral transfection. The overexpressing ING3 lentivirus (LV5-ING3) and the negative control lentivirus (LV5-NC) were synthesized by Shanghai GenePharma Co., Ltd. The breast cancer cells were transduced with lentivirus (LV5-ING3 or LV5-NC), MCF7 and HCC1937 cells were inoculated into 6-well plates at a density of $5 \times 10^{5} / 3 \mathrm{ml} 24 \mathrm{~h}$ prior to transfection. On the day of transfection, $25 \times 10^{5}$ lentivirus was added to MCF7 cells and $50 \times 10^{5}$ lentivirus was added to HCC1937 cells, and polybrene $(8 \mu \mathrm{g} / \mathrm{ml}$; Shanghai GenePharma Co., Ltd.) was added to the culture medium. After $72 \mathrm{~h}$ of screening with puromycin $(1 \mu \mathrm{g} / \mathrm{ml}$; Beijing Solarbio Science \& Technology Co., Ltd.), transfection efficiency was determined via eGFP expression by fluorescence microscopy. Cell viability was determined using the cell counting device (JIMBIO-FIL). Cell suspension $(5 \mu 1)$ was stained with $0.4 \%$ trypan blue dye $(5 \mu \mathrm{l})$ at room temperature and immediately used for cell viability determination; overexpression of ING3 was detected via reverse transcription-quantitative (RT-q)PCR and western blot analyses.

$R T-q P C R$. Total RNA was extracted from breast cancer cells and NBECs using the RNAprep Pure cell kit (Tiangen Biotech Co., Ltd.), and reverse transcribed into cDNA using the FastQuant RT kit with gDNase (Tiangen Biotech Co., Ltd.), the RNA was mixed with the genomic DNA removal system and incubated at $42^{\circ} \mathrm{C}$ for $3 \mathrm{~min}$, following which, the reverse transcription reaction solution was added and incubated at $42^{\circ} \mathrm{C}$ for $15 \mathrm{~min}$ and $95^{\circ} \mathrm{C}$ for $3 \mathrm{~min}$ to synthesize cDNA. qPCR was subsequently performed using SuperReal PreMix Plus (SYBR Green, Tiangen Biotech Co., Ltd.). The following primer sequences were used for qPCR: ING3 forward, 5'-GCT GGATCAGGAACTGGCTAA-3' and reverse, 5'-TCTGTT GTCGTATGGTGAGAAGT-3'; and GAPDH forward, 5'-CAG GAGCGAGATCCCTCCAAAAT-3' and reverse, 5'-AGATGA TGACCCTTTTGGCTCCC-3'. The following thermocycling 
conditions were used for qPCR: $95^{\circ} \mathrm{C}$ for $15 \mathrm{~min}$ for 1 cycle and $95^{\circ} \mathrm{C}$ for $10 \mathrm{sec}$ following $62^{\circ} \mathrm{C}$ for $32 \mathrm{sec}$ for 40 cycles. Relative expression levels were calculated using the $2^{-\Delta \Delta C q}$ method (18) and normalized to the internal reference gene GAPDH.

Western blotting. Total protein was extracted from the cultured cells using RIPA buffer (Beyotime Institute of Biotechnology) and PMSF (Biosharp Life Sciences) mixed at a 100:1 ratio. Total protein was quantified using BCA protein quantification reagent (Beijing Dingguo Changsheng Biotechnology Co., Ltd.). Proteins $(30 \mu \mathrm{g})$ were separated via electrophoresis using Spacer on a $12 \%$ SDS-PAGE gel. The separated proteins were subsequently transferred onto PVDF membranes (EMD Millipore), washed the PVDF membrane with TBST containing 0.1\% Tween-20 and blocked in western blocking fluid (Beyotime Institute of Biotechnology) for $1.5 \mathrm{~h}$ at room temperature. The membranes were incubated with primary antibodies against ING3 (1:1,000 dilution; cat. no. GTX102480; GeneTex, Inc.) and GAPDH (1:5,000 dilution; cat. no. GTX100118; GeneTex, Inc.) at overnight $4^{\circ} \mathrm{C}$. Following the primary incubation, membranes were washed three times with TBST (10 min each), and subsequently incubated with secondary antibody (1:5,000 dilution; cat. no. GTX2131110-01; GeneTex, Inc.) at room temperature for $2 \mathrm{~h}$. Protein bands were visualized using the ECL kit (Suzhou Xinsaimei Biotechnology Co., Ltd.) and analyzed using ImageJ software (1.42q; National Institutes of Health).

Migration and invasion assays. Cells were collected and resuspended in culture medium without serum. For the migration assay, 8x10 $\mathrm{MCF} 7$ cells and HCC1937 cells transfected with LV5-ING3 and LV5-NC were plated in the upper chambers of Transwell plates without Matrigel, cell culture medium containing 20\% FBS (Corning, Inc.) was added to the lower chamber. For the invasion assay, Matrigel was diluted on ice with RPMI-1640 medium (Corning, Inc.) at a ratio of $1: 8$, and solidified at $37^{\circ} \mathrm{C}$ for $2 \mathrm{~h}$. Following coating, $8 \times 10^{4}$ MCF7 cells and HCC1937 cells transfected with LV5-ING3 and LV5-NC were plated in the upper chambers of 8- $\mu \mathrm{m}$ pore size plates coated with $60 \mu \mathrm{l}$ Matrigel, cell culture medium containing 20\% FBS (Corning, Inc.) was added to the lower chamber. Following incubation for $24 \mathrm{~h}$, at $37^{\circ} \mathrm{C}$ with $95 \%$ air and $5 \% \mathrm{CO}_{2}$, the non-invasive and non-migratory cells were removed. The invasive and migratory cells were fixed with $4 \%$ polysorbate $30 \mathrm{~min}$ and stained with Giemsa stain $30 \mathrm{~min}$ at room temperature. Stained cells were counted for quantification and images captured using a light microscope (magnification, x100) (26)

Wound healing assay. Cells transfected with LV5-ING3 and LV5-NC were suspended and seeded into 12-well plates. Following cell adhesion, sterile $200 \mu$ l pipette tips were used to scratch the cell monolayers of each well. Plates were washed with PBS to remove detached cells. Cells were cultured in serum-free medium. Wound closure was observed using a light microscope (magnification, x100) and measured at 0, 12 and $24 \mathrm{~h}$. Image-pro Plus 6.0 software (Media Cybernetics, Inc.) was used to measure the distance of the wound, using the following formula: Percent wound closure $=$ wound closure distance of 12 or $24 \mathrm{~h} /$ wound closure distance of $0 \mathrm{~h}$.

GeneMANIA protein interaction and Kyoto Encyclopedia of Genes and Genomes (KEGG) pathway analyses. Homo ING3 protein and other core protein interactions were analyzed using the GeneMANIA database (http://genemania. org). Pathway analysis was performed using the KEGG database (https://www.kegg.jp). All analyses were completed on March 12, 2020, using the default parameters of the databases.

Statistical analysis. Statistical analysis was performed using SPSS 22.0 software (IBM Corp.) and GraphPad Prism 6.0 software (GraphPad Software, Inc.). Unpaired Student's t-test was used to compare differences between two group, while one-way ANOVA and Bonferroni post hoc test were used to compare differences between multiple groups. Survival analysis was performed using the Kaplan-Meier method and log-rank test. $\mathrm{P}<0.05$ was considered to indicate a statistically significant difference.

\section{Results}

ING3 expression in tissues and prognosis. ING3 expression in breast cancer tissues and normal tissues was determined using TCGA and UALCAN databases. As presented in Fig. 1A, ING3 expression was significantly downregulated in cancer tissues compared with normal tissue $(\mathrm{P}<0.001)$. ING3 was expressed across different races, TNM stages, subclasses, menopause statuses, ages, sex and histological subtypes, as presented in Fig. 1B-H. No difference in ING3 mRNA expression among different stages, menopausal states and sex of patient with breast cancer was observed, however, ING3 mRNA expression was significantly higher in triple negative breast cancer than in luminal and HER2 positive breast cancer $(\mathrm{P}<0.001)$, ING3 mRNA expression was also higher in Caucasians than in African Americans $(\mathrm{P}<0.01)$, the expression of ING3 was also higher in ILC breast cancer than mixed breast cancer $(\mathrm{P}<0.05)$.

The present study investigated whether ING3 expression influences the prognosis of patients with breast cancer. Survival analysis was performed using the UALCAN, TCGA, UCSC Xena and KM-plot databases. Notably, no significant differences in long-term survival were observed between patients with low and high ING3 expression, respectively $(\mathrm{P}=0.360$ by UALCAN; Fig. 2A and $\mathrm{P}=0.078$ by KM-plot; Fig. 2B). However, ING3 expression was significantly associated with prognosis in the luminal A ( $\mathrm{P}=0.0039860$; Fig. 2C) and HER2-enriched ( $\mathrm{P}=0.008149$; Fig. 2E) subtypes. Conversely, ING3 expression was not associated with prognosis in patients with different clinical stages of breast cancer (Fig. 2G-J). In addition, there was no significant difference between luminal $\mathrm{B}$ and basal-like breast cancer (Fig. 2D and F).

ING3 expression in cell lines and lentiviral transduction. The results of the present study demonstrated that both ING3 mRNA and protein expression levels were higher in NBECs compared with MCF7 and HCC1937 cells (Fig. 3C-E). Lentiviral vectors overexpressing ING3 
A

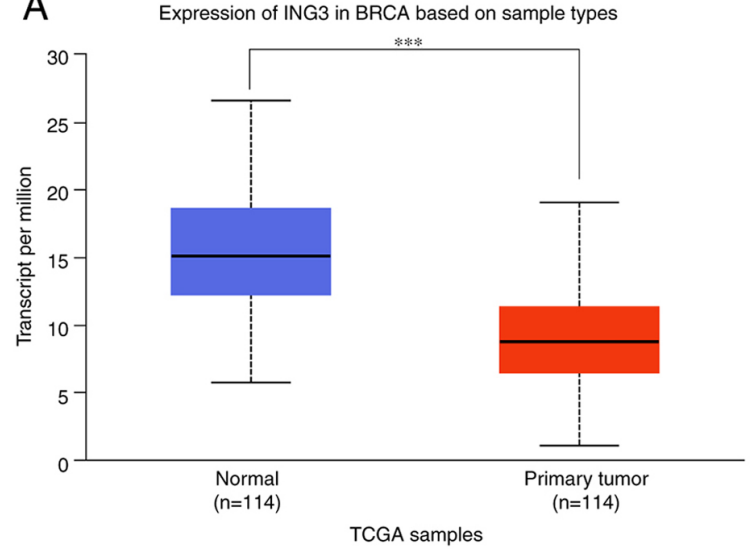

C Expression of ING3 in BRCA based on individual cancer

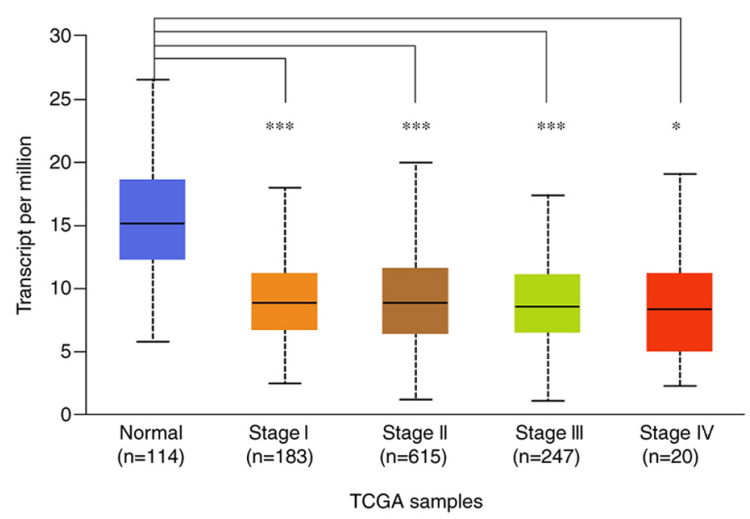

E

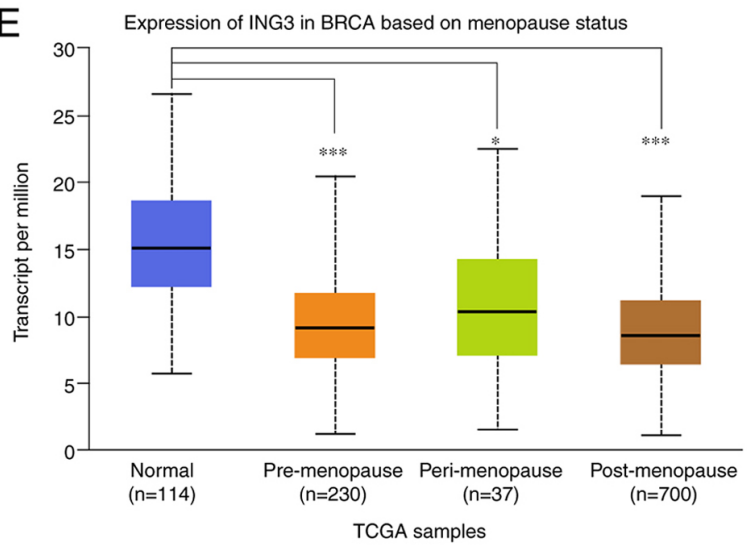

G



B

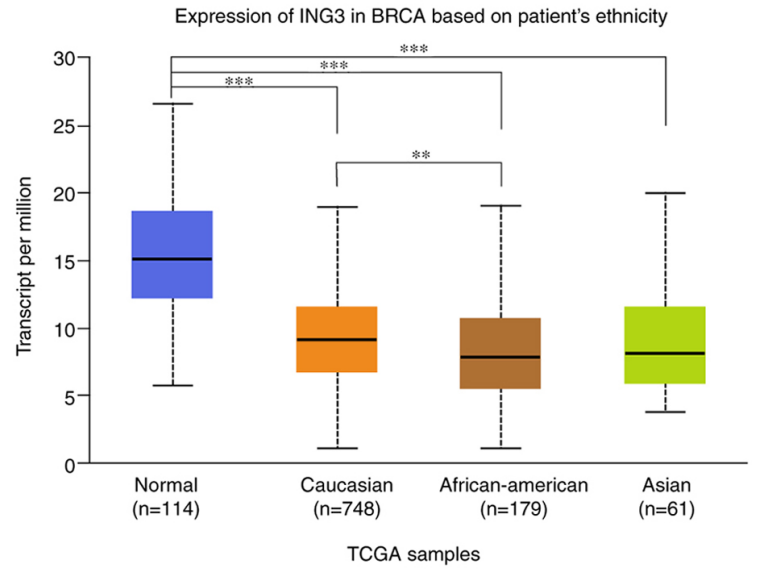

D

Expression of ING3 in BRCA based on breast cancer

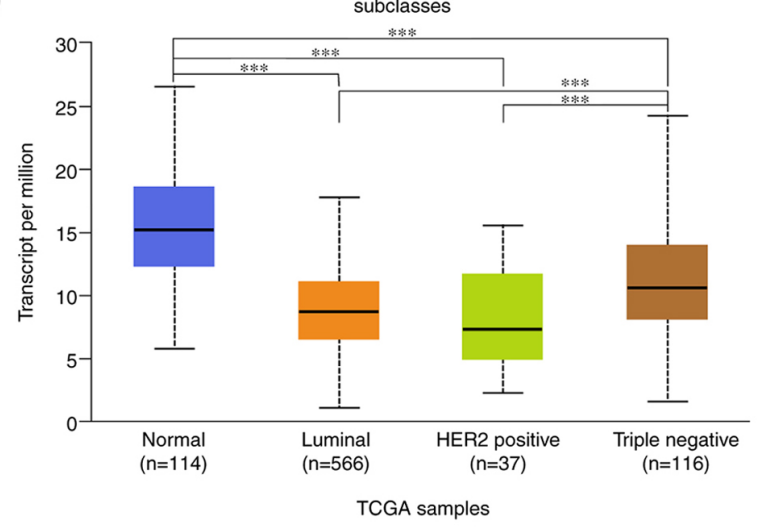

F

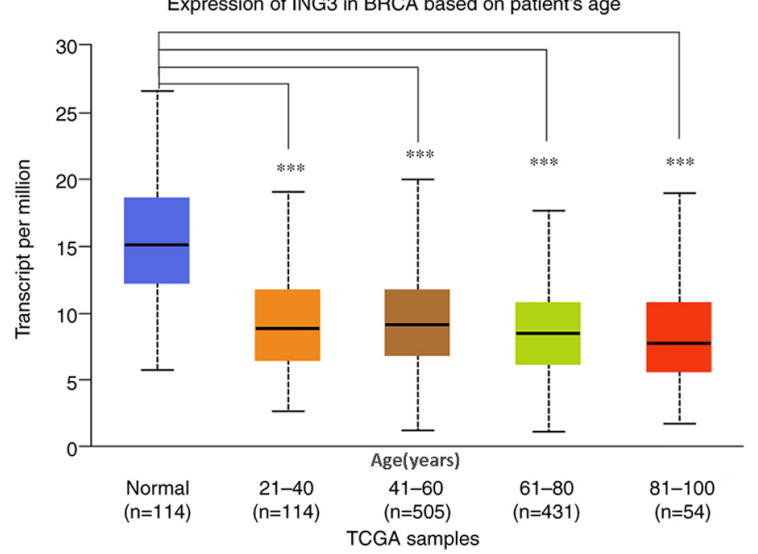

$\mathrm{H}$

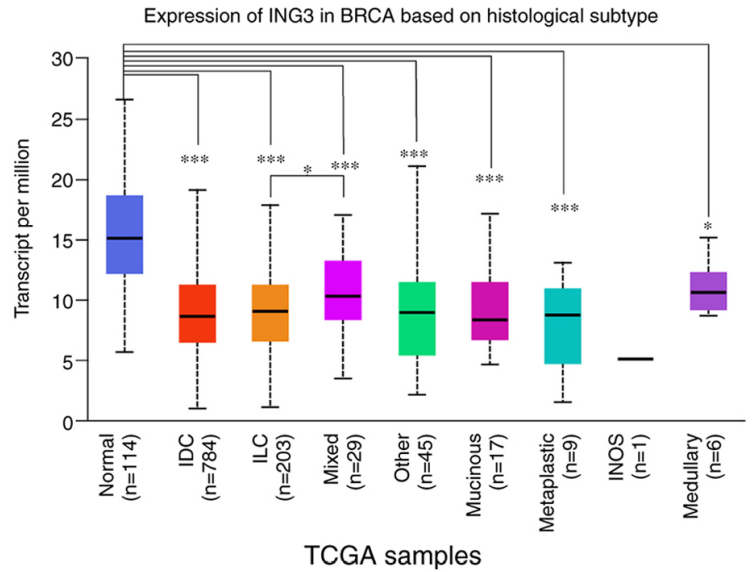

Figure 1.ING3 expression in breast cancer tissues and normal tissues. (A) ING3 expression in breast cancer tissues compared with normal tissues. ING3 expression in normal tissues compared with breast cancer tissues among (B) different races, (C) different tumor-node-metastasis stages, (D) different subclasses, (E) different menopause status, (F) different ages, (G) different sex and (H) different histological subtypes. ${ }^{*} \mathrm{P}<0.05 ;{ }^{* * *} \mathrm{P}<0.01$; ${ }^{* * *} \mathrm{P}<0.001$. ING3, inhibitor of growth 3; TCGA, The Cancer Genome Atlas; HER2, human epidermal growth factor receptor 2; IDC (Infiltrating Ductal Carcinoma), ILC (Infiltrating Lobular Carcinoma), INOS (Infiltrating Carcinoma NOS). 

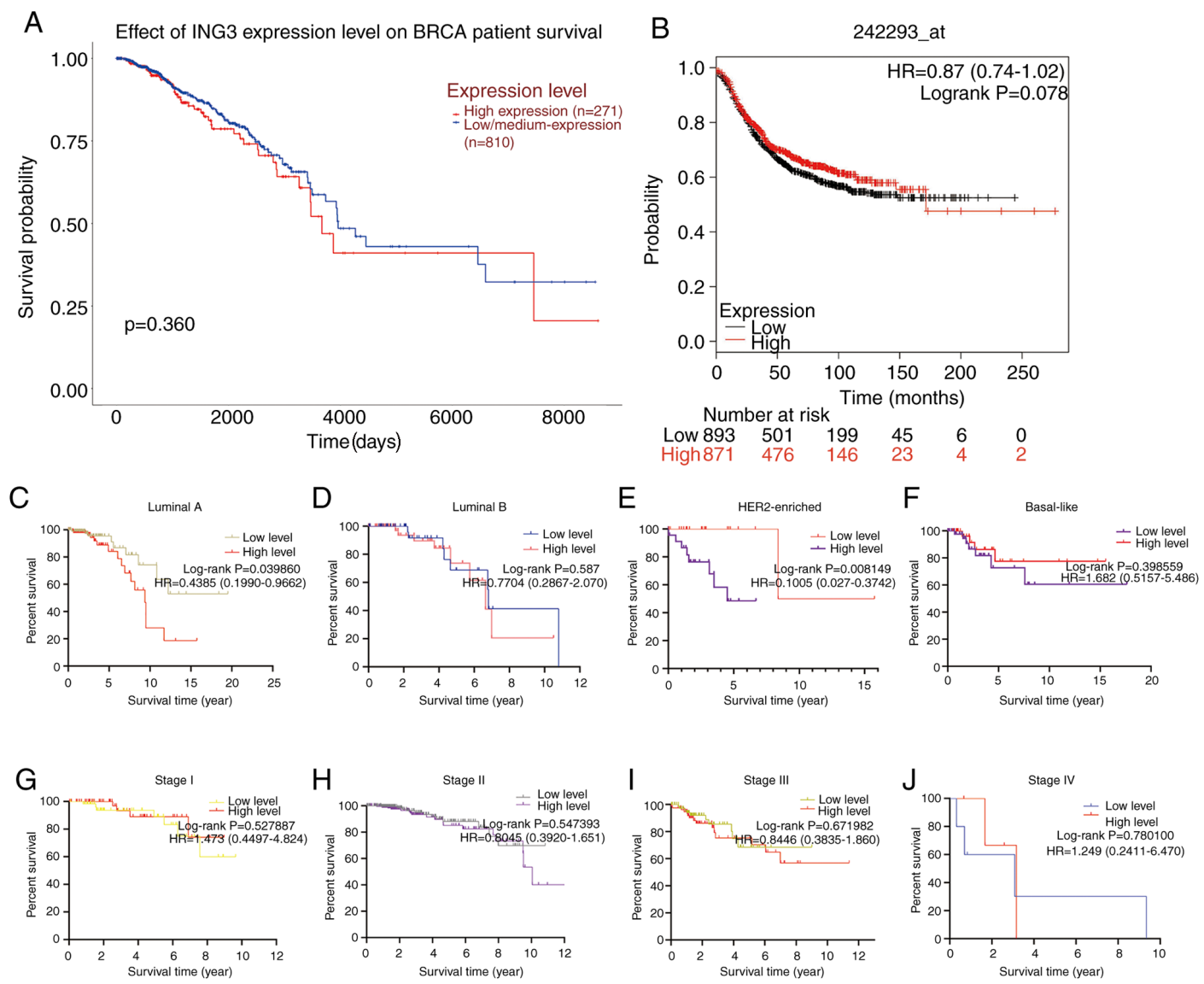

Figure 2. Survival analysis of patients with breast cancer with different $I N G 3$ expression levels. (A) No significant differences were observed in long-term survival between patients with low and high ING3 expression levels, according to (A) UALCAN and (B) KM-plot. (C-F) Long-term survival analysis in different subclasses of patients with low and high ING3 expression levels. (G-J) Long-term survival analysis in different tumor-node-metastasis stages of patients with low and high ING3 expression levels. ING3, inhibitor of growth 3; HER2, human epidermal growth factor receptor 2; HR, hazard ratio.

A



HCC1937

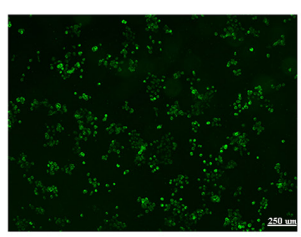

B

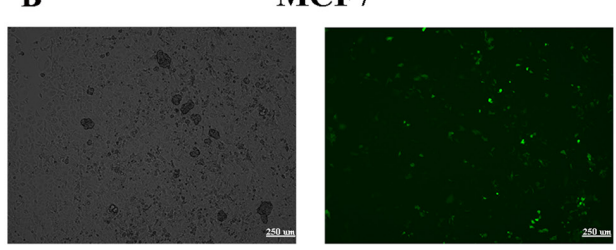

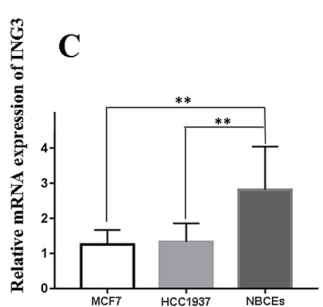

D



G
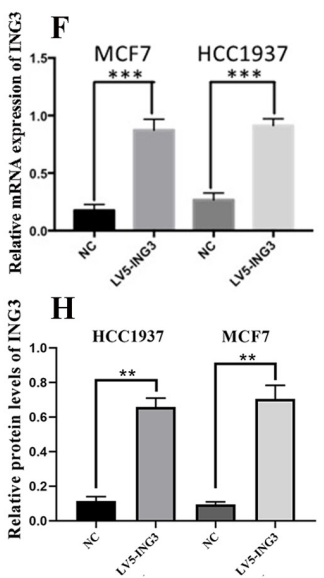

Figure 3. ING3 expression in cell lines and following transfection. Transfection efficiency of (A) HCC1937 and (B) MCF7 cells was detected via eGFP expression by fluorescence microscopy. (C) ING3 mRNA expression was higher in NBECs compared with MCF7 and HCC1937 cells. (D and E) ING3 protein expression was higher in NBECs compared with MCF7 and HCC1937 cells. (F) ING3 mRNA expression was higher in MCF7 and HCC1937 cells transfected with LV5-ING3 compared with the LV5-NC group. (G and H) ING3 protein expression was higher in MCF7 and HCC1937 cells transfected with LV5-ING3 compared with the LV5-NC group. ${ }^{* *} \mathrm{P}<0.01 ;{ }^{* * *} \mathrm{P}<0.001$. ING3, inhibitor of growth 3; NBECs, normal breast epithelial cells; NC, negative control. 




NC



NC

C

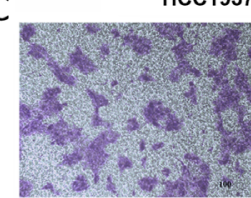

NC

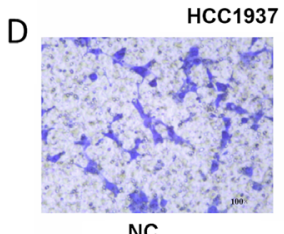

NC

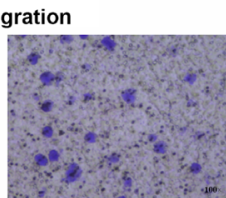

LV5-ING3

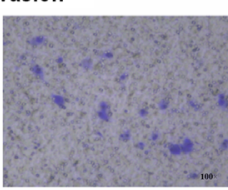

LV5-ING3

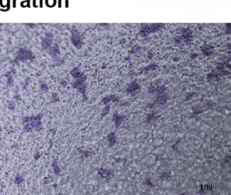

LV5-ING3

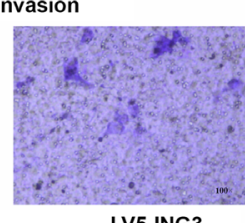

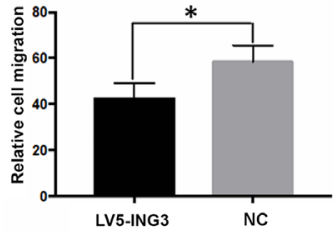
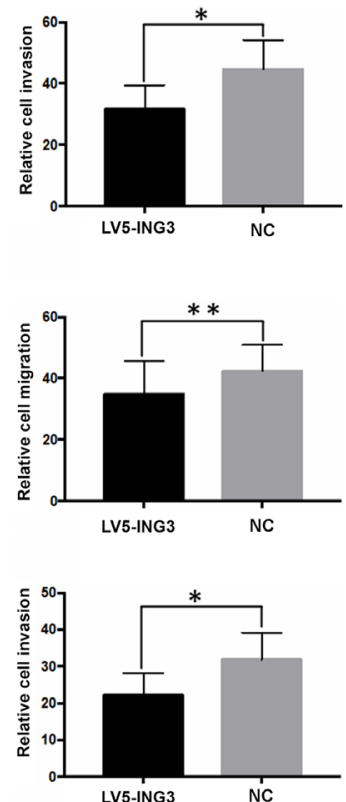

Figure 4. Overexpression of ING3 inhibits migration and invasion. Overexpression of ING3 inhibited the (A) migratory and (B) invasive abilities of MCF7 cells. Overexpression of ING3 inhibited the (C) migratory and (D) invasive abilities of HCC1937 cells. ${ }^{*} \mathrm{P}<0.05$; ${ }^{* *} \mathrm{P}<0.01$. ING3, inhibitor of growth 3 ; NC, negative control.

A

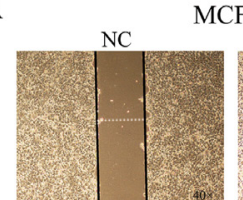

MCF7
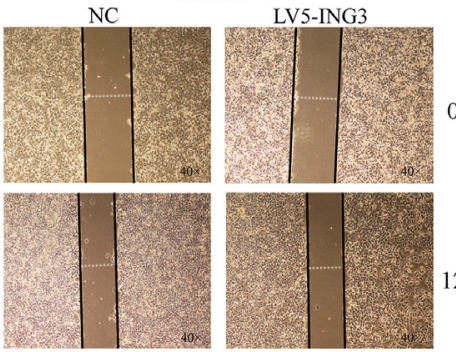

$0 \mathrm{~h}$
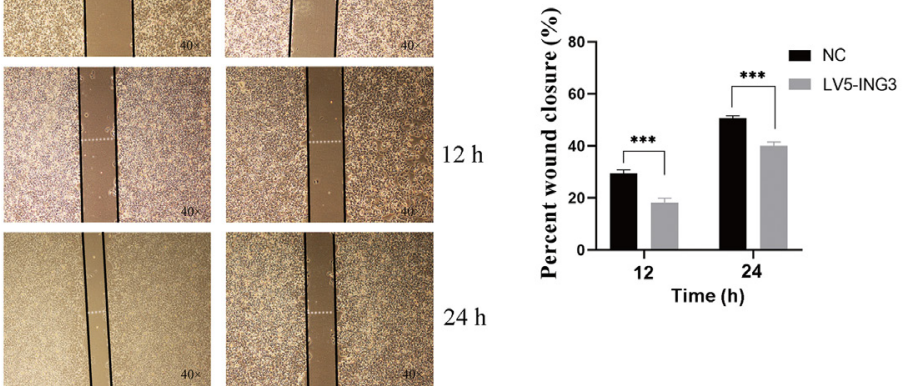

B

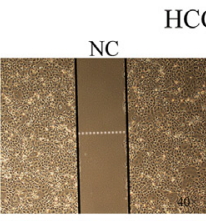

CC1937
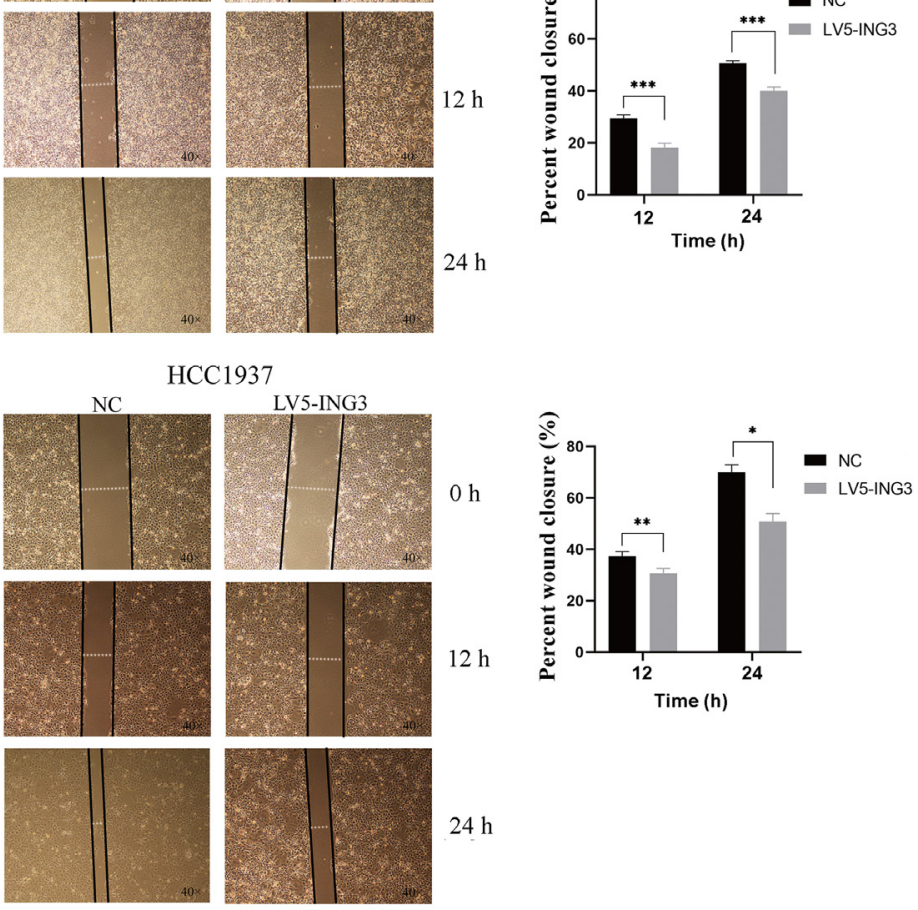

$24 \mathrm{~h}$

Figure 5. Overexpression of ING3 attenuates the percentage wound closure. Overexpression of ING3 attenuated the percentage wound closure in (A) MCF7 and (B) HCC1937 cells after 12 and $24 \mathrm{~h} .{ }^{*} \mathrm{P}<0.05 ;{ }^{* * *} \mathrm{P}<0.01 ;{ }^{* * *} \mathrm{P}<0.001$. ING3, inhibitor of growth 3; NC, negative control. 

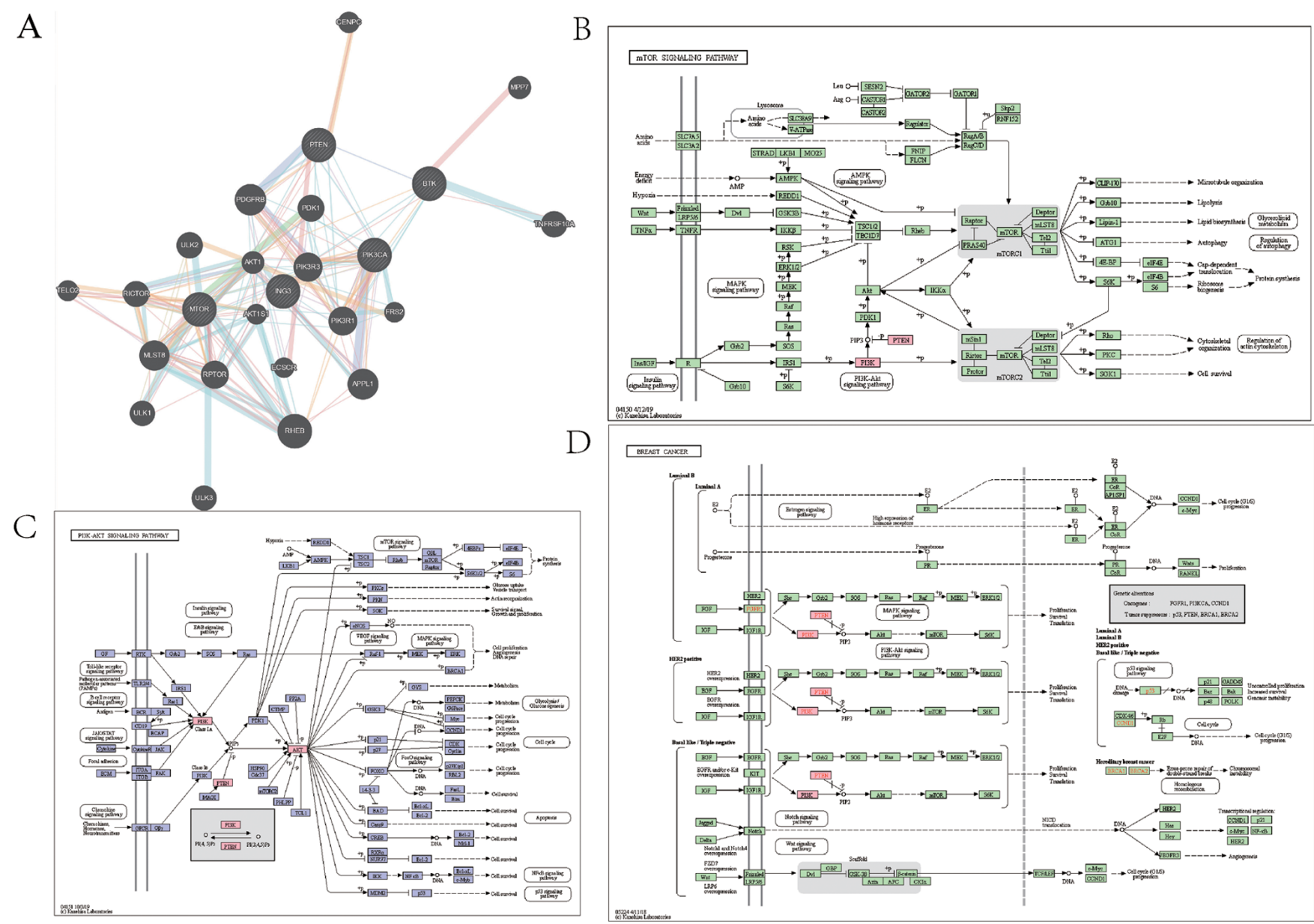

Figure 6. Potential pathway regulated by ING3. (A) GeneMANIA analysis revealed interaction between ING3 and a core protein of the PI3K/ AKT pathway, while Kyoto Encyclopedia of Genes and Genomes pathway analysis demonstrated that ING3 may regulate the PI3K/AKT pathway. (B) PI3K/Akt Pathway was involved in mTOR signaling. (C) PI3K/Akt Pathway. (D) PI3K/ Akt pathway involved in breast cancer. ING3, inhibitor of growth 3 .

(LV5-ING3) and LV5-NC were transfected into MCF7 and HCC1937 cells. No significant differences were observed in cell viability following transfection with the corresponding lentivirus vectors (Fig. S1). The transfection efficiency was detected via eGFP expression by fluorescence microscopy (Fig. 3A and B). The mRNA and protein expression levels of ING3 increased in MCF7 and HCC1937 cells following transfection with LV5-ING3 compared with the LV5-NC group (Fig. 3F-H).

Overexpression of ING3 inhibits migration and invasion. Overexpression of ING3 inhibited the migratory and invasive abilities of MCF7 cells. The average migration cell counts were $41 \pm 8$ for the LV5-ING3 group compared with $58 \pm 6$ for the $\mathrm{NC}$ group $(\mathrm{P}<0.05$; Fig. $4 \mathrm{~A})$. The average invasion cell counts were $33 \pm 7$ for the LV5-ING3 group compared with $42 \pm 8$ for the $\mathrm{NC}$ group $(\mathrm{P}<0.05$; Fig. $4 \mathrm{~B})$. Furthermore, overexpression of $I N G 3$ inhibited the migratory and invasive abilities of HCC1937 cells. The average migration cell counts were $37 \pm 7$ for the LV5-ING3 group compared with $41 \pm 6$ for the NC group $(\mathrm{P}<0.01$; Fig. $4 \mathrm{C})$. The average invasion cell counts were $23 \pm 6$ for the LV5-ING3 group compared with $32 \pm 7$ for the NC group $(\mathrm{P}<0.05$; Fig. 4D).
The results of the wound healing assay suggested a similar phenomenon. In MCF7 cells, the percentage wound closure was $18.16 \pm 1.76$ in the LV5-ING3 group vs. $29.40 \pm 1.37$ in the NC group in $12 \mathrm{~h}(\mathrm{P}<0.001$; Fig. $5 \mathrm{~A})$. Furthermore, the percentage wound closure was $40.03 \pm 1.48$ in the LV5-ING3 group vs. $50.63 \pm 0.95$ in the $\mathrm{NC}$ group in $24 \mathrm{~h}$ ( $\mathrm{P}<0.001$; Fig. 5A). In HCC1937 cells, the percentage wound closure was $30.69 \pm 1.85$ in the LV5-ING3 group vs. $37.35 \pm 1.78$ in the $\mathrm{NC}$ group at $12 \mathrm{~h}(\mathrm{P}<0.01$; Fig. $5 \mathrm{~B})$. Furthermore, the percentage wound closure was $50.76 \pm 3.22$ in the LV5-ING3 group vs. $70.03 \pm 2.89$ in the NC group at $24 \mathrm{~h}(\mathrm{P}<0.05$; Fig. 5B).

Potential pathways regulated by ING3. The present study aimed to investigate the potential regulating mechanism of ING3. The PI3K/AKT, JAK/STAT, NF-кB and Wnt/B-catenin pathways are closely associated with different types of cancer, including breast cancer (27-33). In the present study, GeneMANIA analysis exhibited interaction between ING3 and the core protein of the PI3K/AKT pathway, while KEGG pathway analysis demonstrated that ING3 may regulate the PI3K/AKT pathway (Fig. 6). Similar results were observed

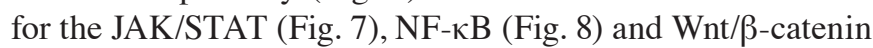
(Fig. 9) pathways. 
A

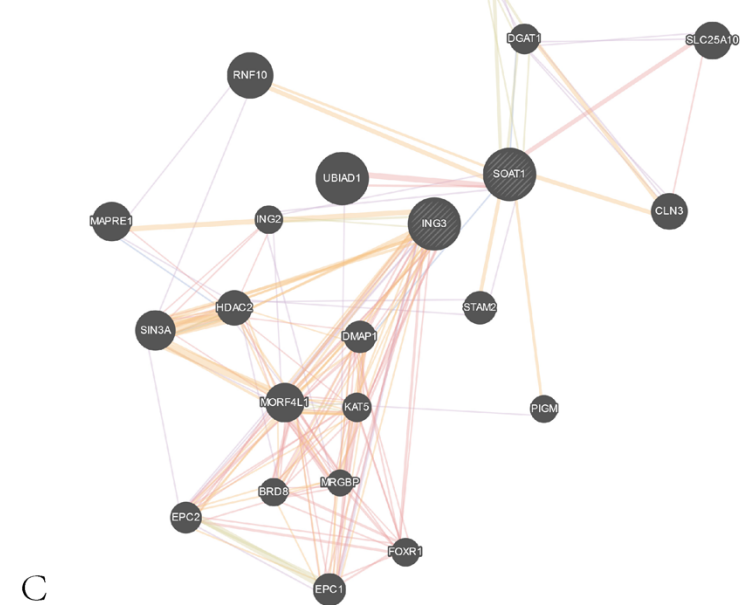

B
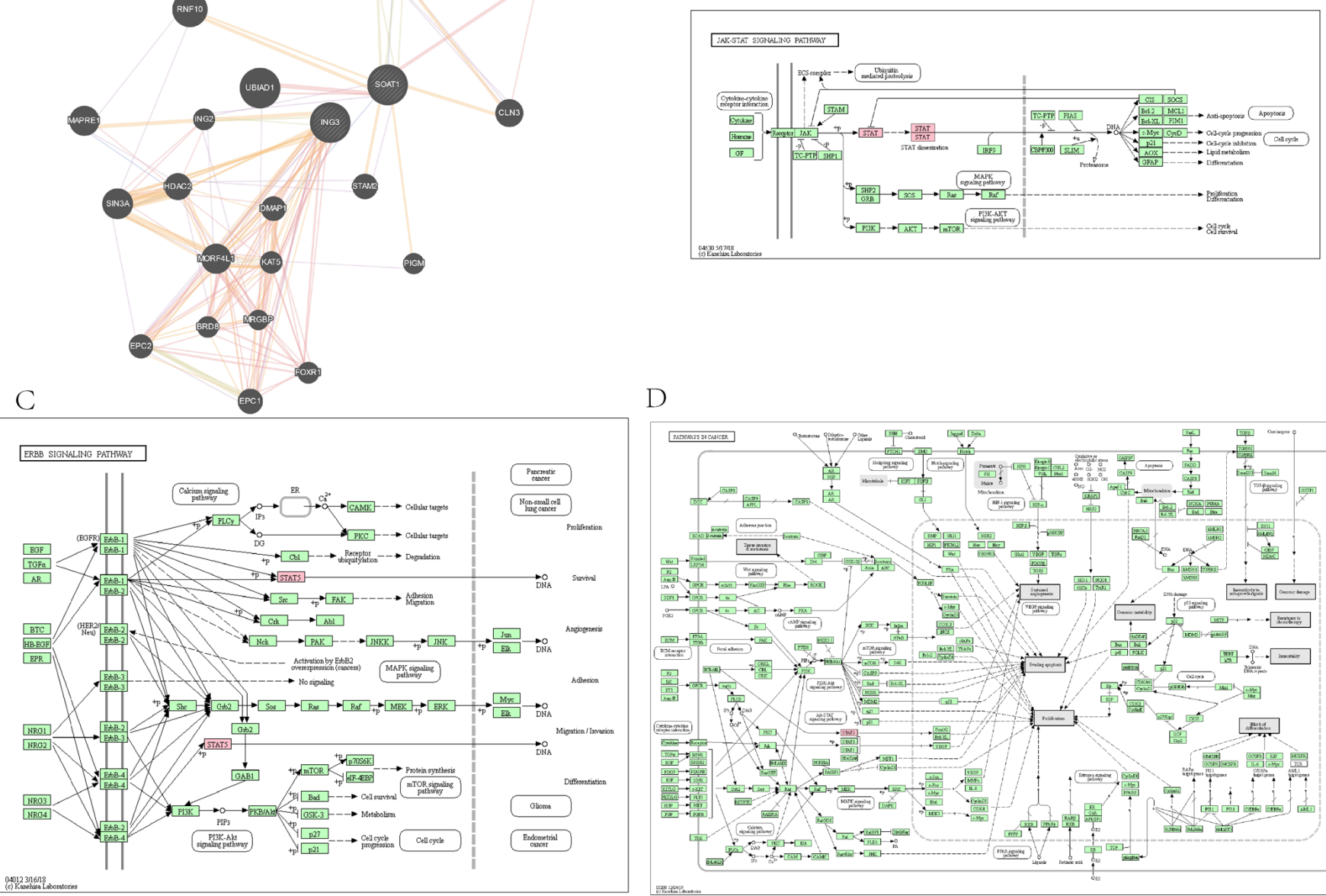

$\mathrm{D}$

Figure 7. Potential pathway regulated by ING3. (A) GeneMANIA analysis revealed interaction between ING3 and a core protein of the JAK/STAT pathway, while Kyoto Encyclopedia of Genes and Genomes pathway analysis demonstrated that ING3 may regulate the JAK/STAT pathway. (B) The JAK/ STAT pathway. (C) The JAK/STAT pathway is involved in ERBB signaling. (D) The JAK/STAT pathway is involved in breast cancer. ING3, inhibitor of growth 3 .

\section{Discussion}

Data from TCGA and UALCAN databases confirmed that ING3 expression is downregulated in breast cancer tissues compared with normal breast tissues, and similar results were observed in breast cancer cell lines and NBECs. In the present study, ING3 had prognostic significance in certain types of breast cancer, such as luminal A and HER2-enriched breast cancer. To the best of the authors' knowledge, the present study was the first to demonstrate that overexpression of ING3 inhibits the migratory and invasive abilities of breast cancer cells. The results demonstrated that the PI3K/AKT, JAK/STAT, NF- $\mathrm{BB}$ and $\mathrm{Wnt} / \beta$-catenin pathways are potential pathways regulated by ING3.

Studies investigating the association between ING3 and cancer are gaining significant interest (18,34-36). Increasing evidence suggest that ING3 is a key protein in cell apoptosis (37), cell proliferation and renewal (36), and tumor biological behaviors (18). Yang et al (35) reported that ING3 expression is downregulated in gastric cancer. However, Nabbi et al (19) demonstrated that ING3 expression is upregulated in prostate cancer. The role of ING3 in breast cancer remains largely unknown. The present study compared ING3 expression across different races, TNM stages, subclasses, menopause status, ages, sex and histological subtypes. Notably, no significant differences were observed in the respective comparisons. To the best of our knowledge, the present study is the first to reveal that ING3 may act as a tumor suppressor gene in breast cancer. The results of the present study differ from previous findings on prostate cancer $(18,19)$, but are similar to studies on head and neck cancer $(16,23)$.

The results of the present study suggest that ING3 may be a prognostic biomarker for patients with breast cancer. In the present study, high ING3 expression predicted poor prognosis in patients with luminal A and HER2-enriched breast cancer. However, ING3 expression was not associated with prognosis in patients with breast cancer without classification, and no significant association was observed between ING3 expression and prognosis in patients with different clinical stages.

Metastasis is a key feature of malignancies $(38,39)$. Migration and invasion initiate metastasis in vitro (40-42). ING3 is considered a tumor suppressor in hepatocellular carcinoma, which attenuates proliferation, migration and invasion (17). However, it is considered a tumorigenesis promoter 

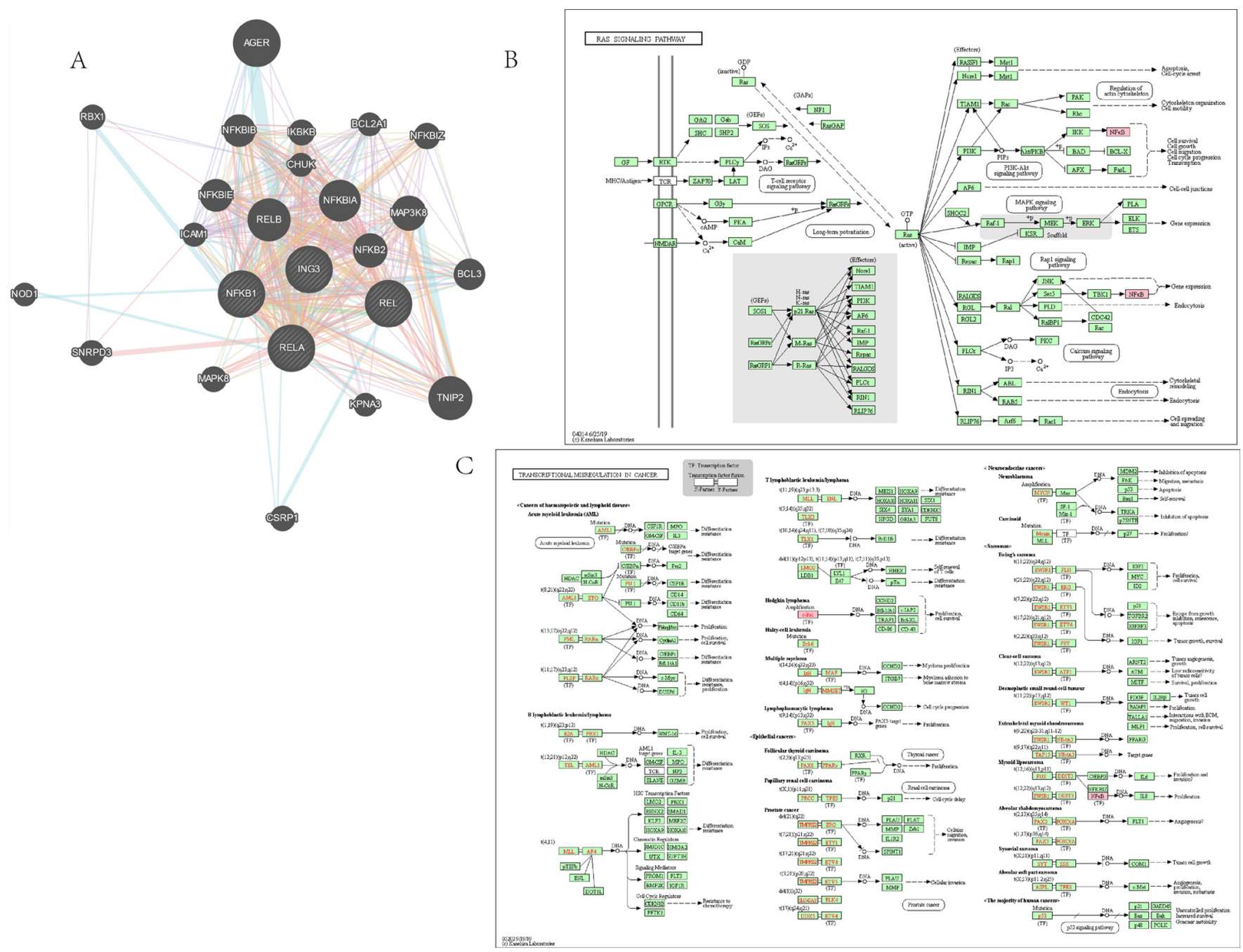

Figure 8. Potential pathway regulated by ING3. (A) GeneMANIA analysis revealed interaction between ING3 and a core protein of the NF- $\kappa B$ pathway, while Kyoto Encyclopedia of Genes and Genomes pathway analysis demonstrated that ING3 may regulate the NF- $\mathrm{kB}$ pathway. (B) The

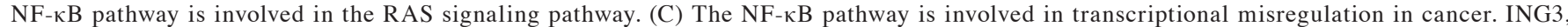
inhibitor of growth 3 .

in prostate cancer $(18,19)$. The results of the present study demonstrated that ING3 mRNA and protein expression levels were higher in NBECs compared with MCF7 and HCC1937 cells. Similar results were observed between breast cancer tissues and normal tissues. The results of the Transwell migration and invasion, and wound healing assays demonstrated that overexpression of ING3 inhibited the migratory and invasive abilities of MCF7 cells. Collectively, these results suggest that ING3 acts as a tumor suppressor in breast cancer, influencing biological behaviors, particularly attenuating migration and invasion.

In the present study, high ING3 mRNA expression was associated with poor prognosis, while overexpression of ING3 inhibited the metastasis of breast cancer cells. However, gene expression is a complex biological process, and further studies are required to validate gene function at the mRNA level, as only a weak association was observed between mRNA and protein expression $(43,44)$. Previous studies have demonstrated that ING3 protein can be rapidly degraded by the $\mathrm{SCF}^{\text {skp2}}$-mediated ubiquitin-protease system $(45,46)$. Thus, prospective studies will focus on investigating the association between ING3 protein expression and prognosis.

Studying the mechanisms of metastasis is important in identifying novel anti-cancer drugs and developing cancer therapy (47-49). The activation of cancer-related pathways as a promotor of tumorigenesis, proliferation, migration and invasion in several types of cancer is generally accepted $(50,51)$. ING3 regulates cell proliferation, apoptosis and cell cycle in gastric cancer via the PI3K/AKT pathway (23). However, the mechanisms by which ING3 regulates pathways in breast cancer remain unclear. The results of the present study revealed interactions between ING3 and core proteins of the PI3K/AKT, JAK/STAT, $\mathrm{NF}-\kappa \mathrm{B}$ and $\mathrm{Wnt} / \beta$-catenin pathways. In addition, KEGG pathway analysis indicated that ING3 potentially regulates the PI3K/AKT, JAK/STAT, NF- $\mathrm{BB}$ and Wnt/ $\beta$-catenin pathways. Although these assumptions were not proven in the present study, they remain valid hypotheses and will be the focus of prospective studies.

In conclusion, the results of the present study suggest that ING3 plays a key role in breast cancer. ING3 expression 


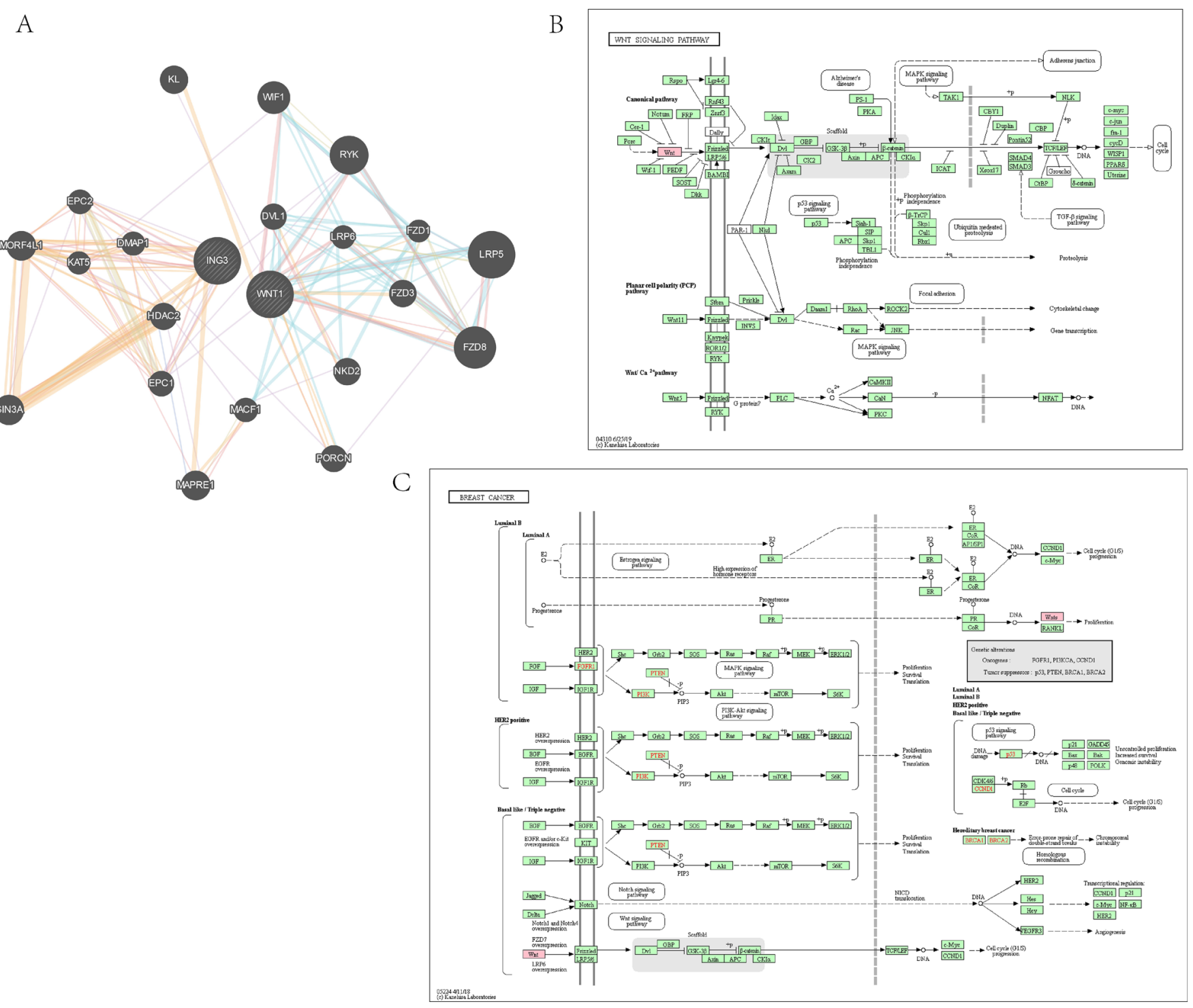

Figure 9. Potential pathway regulated by ING3. (A) GeneMANIA analysis revealed interaction between ING3 and a core protein of the Wnt/ $\beta$-catenin pathway, while Kyoto Encyclopedia of Genes and Genomes pathway analysis demonstrated that ING3 may regulate the Wnt/B-catenin pathway. (B) Wnt signaling pathway. (C) Wnt signaling pathway involved in breast cancer. ING3, inhibitor of growth 3.

was downregulated in breast cancer tissues compared with normal tissues. In addition, ING3 expression influenced the prognosis of patients with different molecular subtypes. Notably, overexpression of ING3 inhibited migration and invasion in vitro. Thus, ING3 may be used to regulate the biological behavior of breast cancer via tumor-related pathways.

\section{Acknowledgements}

Not applicable.

\section{Funding}

The present study was supported by the National Natural Science Foundation of China (grant nos. 81960542 and 81960517), the Science and Technology Project of Yunnan Provincial Science and Technology Department (grant nos. 202001AU070053 and 202001AU070093), the
ScientificResearchFoundationofYunnanEducationDepartment (grant nos. 2019J1288 and 2020J0198), the Research Institution Project of the Health Science and Technology Plan of Yunnan Province (grant no. 2018NS0055) and the Yunnan Health Training Project of High Level Talents (grant no. H-2019075).

\section{Availability of data and materials}

All data generated or analyzed during this study are included in this published article.

\section{Authors' contributions}

The study was designed by ST, RL, DL and HZ. DL, MW, YT, $\mathrm{KZ}$ and WC carried out the funding obtain and manuscript review. HL (first author), RG, DL, RL downloaded the gene expression and clinical data from the TCGA database.ST, HL (first author), XT in charge of bioinformatics analysis. HZ, YT and $\mathrm{WC}$ is responsible for cell transfection, molecular biology 
experiments and cell function experiments. The data were statistically analyzed by MW, KZ, HL, MT and KW. HL(first author) and ST write the manuscript, and all authors participate in the revision. ST and HZ confirm the authenticity of all the raw data. All authors reviewed and approved the final manuscript.

\section{Ethics approval and consent to participate}

The present study was approved by the Ethics Committees of the Third Affiliated Hospital of Kunming Medical University, Yunnan Cancer Hospital, Kunming, China; approval no. QT202002, and written informed consent was provided by all patients prior to the beginning of the study.

\section{Patient consent for publication}

Not applicable.

\section{Competing interests}

The authors declare that they have no competing interests.

\section{References}

1. Siegel RL, Miller KD and Jemal A: Cancer statistics, 2020 CA Cancer J Clin 70: 7-30, 2020.

2. DeSantis CE, Ma J, Gaudet MM, Newman LA, Miller KD, Goding Sauer A, Jemal A and Siegel RL: Breast cancer statistics, 2019. CA Cancer J Clin 69: 438-451, 2019.

3. Sung H, Ferlay J, Siegel RL, Laversanne M, Soerjomataram I, Jemal A and Bray F: Global cancer statistics 2020: GLOBOCAN estimates of incidence and mortality worldwide for 36 cancers in 185 countries. CA Cancer J Clin: Feb 4, 2021 (Epub ahead of print). doi: $10.3322 /$ caac. 21660 .

4. Schwartz RS and Erban JK: Timing of metastasis in breast cancer. N Engl J Med 376: 2486-2488, 2017.

5. Mouche A, Archambeau J, Ricordel C, Chaillot L, Bigot N, Guillaudeux T, Grenon M and Pedeux R: ING3 is required for ATM signaling and DNA repair in response to DNA double strand breaks. Cell Death Differ 26: 2344-2357, 2019.

6. Ludwig S, Klitzsch A and Baniahmad A: The ING tumor suppressors in cellular senescence and chromatin. Cell Biosci 1: 25, 2011.

7. Gou WF, Yang XF, Shen DF, Zhao S, Sun HZ, Luo JS and Zheng HC: Immunohistochemical profile of ING3 protein in normal and cancerous tissues. Oncol Lett 13: 1631-1636, 2017.

8. Shiseki M, Nagashima M, Pedeux RM, Kitahama-Shiseki M, Miura K, Okamura S, Onogi H, Higashimoto Y, Appella E, Yokota J and Harris CC: p29ING4 and p28ING5 bind to p53 and p300, and enhance p53 activity. Cancer Res 63: 2373-2378, 2003

9. Bose P, Thakur SS, Brockton NT, Klimowicz AC, Kornaga E, Nakoneshny SC, Riabowol KT and Dort JC: Tumor cell apoptosis mediated by cytoplasmic ING1 is associated with improved survival in oral squamous cell carcinoma patients. Oncotarget 5: 3210-3219, 2014

10. Zhang R, Jin J, Shi J and Hou Y: INGs are potential drug targets for cancer. J Cancer Res Clin Oncol 143: 189-197, 2017.

11. Dantas A, Al Shueili B, Yang Y, Nabbi A, Fink D and Riabowol K: Biological functions of the ING proteins. Cancers (Basel) 11: 1817, 2019.

12. Liu XL, Meng J, Zhang XT, Liang XH, Zhang F, Zhao GR and Zhang T: ING5 inhibits lung cancer invasion and epithelial-mesenchymal transition by inhibiting the WNT/ $\beta$-catenin pathway. Thorac Cancer 10: 848-855, 2019

13. Liu XL, Zhang XT, Meng J, Zhang HF, Zhao Y, Li C, Sun Y, Mei QB, Zhang $F$ and Zhang T: ING5 knockdown enhances migration and invasion of lung cancer cells by inducing EMT via EGFR/PI3K/Akt and IL-6/STAT3 signaling pathways. Oncotarget 8: 54265-54276, 2017.

14. Cai L, Li H, Chen C, Cheng X, Wang Y, Liu J, Wang Y and Hao L: Role of inhibitor of growth 4 in the suppression of human melanoma cells through the Fas/FasL-mediated apoptosis pathway. Int J Mol Med 41: 1055-1061, 2018.
15. Suzuki S, Nozawa Y, Tsukamoto S, Kaneko T, Imai H and Minami N: ING3 is essential for asymmetric cell division during mouse oocyte maturation. PLoS One 8: e74749, 2013.

16. Li X, Zhang Q, Zhang M, Luo Y and Fu Y: Downregulation of nuclear ING3 expression and translocalization to cytoplasm promotes tumorigenesis and progression in head and neck squamous cell carcinoma (HNSCC). Histol Histopathol 35: 681-690, 2020.

17. Lu M, Chen F, Wang Q, Wang K, Pan Q and Zhang X: Downregulation of inhibitor of growth 3 is correlated with tumorigenesis and progression of hepatocellular carcinoma. Oncol Lett 4: 47-52, 2012

18. McClurg UL, Nabbi A, Ricordel C, Korolchuk S, McCracken S, Heer R, Wilson L, Butler LM, Irving-Hooper BK, Pedeux R, et al: Human ex vivo prostate tissue model system identifies ING3 as an oncoprotein. Br J Cancer 118: 713-726, 2018.

19. Nabbi A, McClurg UL, Thalappilly S, Almami A, Mobahat M, Bismar TA, Binda O and Riabowol KT: ING3 promotes prostate cancer growth by activating the androgen receptor. BMC Med 15: 103, 2017.

20. Wang Y, Dai DL, Martinka M and Li G: Prognostic significance of nuclear ING3 expression in human cutaneous melanoma. Clin Cancer Res 13: 4111-4116, 2007.

21. Zhou R, Rotte A, Li G, Chen X, Chen G and Bhandaru M: Nuclear localization of ING3 is required to suppress melanoma cell migration, invasion and angiogenesis. Biochem Biophys Res Commun 527: 418-424, 2020.

22. Wu X, Chen C, Luo B, Yan D, Yan H, Chen F, Guan F, Wu H and Yuan J: Nuclear ING3 expression is correlated with a good prognosis of breast cancer. Front Oncol 10: 589009, 2020.

23. Zhao S, Wang L, Zhang C, Deng Y, Zhao B, Ren Y, Fu Y and Meng X: Inhibitor of growth 3 induces cell death by regulating cell proliferation, apoptosis and cell cycle arrest by blocking the PI3K/AKT pathway. Cancer Gene Ther 25: 240-247, 2018.

24. Team C. Team RDC.R: A Language and environment for statistical computing. R Foundation for Statistical Computing, Vienna, Austria, 2012.

25. Edge SB and Compton CC: The American Joint Committee on Cancer: The 7th edition of the AJCC cancer staging manual and the future of TNM. Ann Surg Oncol 17: 1471-1474, 2010.

26. Tang S, Pan H, Wei W, Yang H, Liu J and Yang R: GOLPH3: A novel biomarker that correlates with poor survival and resistance to chemotherapy in breast cancer. Oncotarget 8: 105155-105169, 2017.

27. Mayer IA and Arteaga CL: The PI3K/AKT pathway as a target for cancer treatment. Annu Rev Med 67: 11-28, 2016.

28. Torres-Arzayus MI, Font de Mora J, Yuan J, Vazquez F, Bronson R, Rue M, Sellers WR and Brown M: High tumor incidence and activation of the PI3K/AKT pathway in transgenic mice define AIB1 as an oncogene. Cancer Cell 6: 263-274, 2004

29. Laurent C, Nicolae A, Laurent C, Le Bras F, Haioun C, Fataccioli V, Amara N, Adélaïde J, Guille A, Schiano JM, et al: Gene alterations in epigenetic modifiers and JAK-STAT signaling are frequent in breast implant-associated ALCL. Blood 135: 360-370, 2020.

30. Jiang L, Zhao XH, Mao YL, Wang JF, Zheng HJ and You QS: Long non-coding RNA RP11-468E2.5 curtails colorectal cancer cell proliferation and stimulates apoptosis via the JAK/STAT signaling pathway by targeting STAT5 and STAT6. J Exp Clin Cancer Res 38: 465, 2019.

31. Davis RT, Blake K, Ma D, Gabra M, Hernandez GA, Phung AT, Yang Y, Maurer D, Lefebvre A, Alshetaiwi H, et al: Transcriptional diversity and bioenergetic shift in human breast cancer metastasis revealed by single-cell RNA sequencing. Nat Cell Biol 22: 310-320, 2020.

32. Matsumoto S, Yamamichi T, Shinzawa K, Kasahara Y, Nojima S, Kodama T, Obika S, Takehara T, Morii E, Okuyama H, et al: GREB1 induced by Wnt signaling promotes development of hepatoblastoma by suppressing TGF $\beta$ signaling. Nat Commun 10: $3882,2019$.

33. Wellenstein MD, Coffelt SB, Duits D, van Miltenburg MH, Slagter M, de Rink I, Henneman L, Kas SM, Prekovic S, Hau CS, et al: Loss of p53 triggers WNT-dependent systemic inflammation to drive breast cancer metastasis. Nature 572: 538-542, 2019.

34. Fink D, Yau T, Nabbi A, Wagner B, Wagner C, Hu SM, Lang V, Handschuh S, Riabowol K and Rülicke T: Loss of Ing3 expression results in growth retardation and embryonic death. Cancers (Basel) 12: 80, 2019. 
35. Yang C, Gao J, Yan N, Wu B, Ren Y, Li H and Liang J: Propofol inhibits the growth and survival of gastric cancer cells in vitro through the upregulation of ING3. Oncol Rep 37: 587-593, 2017.

36. Nabbi A, Almami A, Thakur S, Suzuki K, Boland D, Bismar TA and Riabowol K: ING3 protein expression profiling in normal human tissues suggest its role in cellular growth and self-renewal. Eur J Cell Biol 94: 214-222, 2015.

37. Luo J, Shah S, Riabowol K and Mains PE: The Caenorhabditis elegans ing-3 gene regulates ionizing radiation-induced germ-cell apoptosis in a p53-associated pathway. Genetics 181: 473-482, 2009.

38. Padmanaban V, Krol I, Suhail Y, Szczerba BM, Aceto N, Bader JS and Ewald AJ: E-cadherin is required for metastasis in multiple models of breast cancer. Nature 573: 439-444, 2019.

39. Zeng Q, Michael IP, Zhang P, Saghafinia S, Knott G, Jiao W, McCabe BD, Galván JA, Robinson H, Zlobec I, et al: Synaptic proximity enables NMDAR signalling to promote brain metastasis. Nature 573: 526-531, 2019.

40. Chen L, Yang S, Jakoncic J, Zhang JJ and Huang XY: Migrastatin analogues target fascin to block tumour metastasis. Nature 464: 1062-1066, 2010.

41. Ma L, Teruya-Feldstein J and Weinberg RA: Tumour invasion and metastasis initiated by microRNA-10b in breast cancer. Nature 449: 682-688, 2007

42. Goetz JG, Minguet S, Navarro-Lérida I, Lazcano JJ, Samaniego R, Calvo E, Tello M, Osteso-Ibáñez T, Pellinen T, Echarri A, et al: Biomechanical remodeling of the microenvironment by stromal caveolin-1 favors tumor invasion and metastasis. Cell 146: 148-163, 2011.

43. de Sousa Abreu R, Penalva LO, Marcotte EM and Vogel C: Global signatures of protein and mRNA expression levels. Mol Biosyst 5: 1512-1526, 2009.

44. Maier T, Güell M and Serrano L: Correlation of mRNA and protein in complex biological samples. FEBS Lett 583: 3966-3973, 2009.
45. Chen G, Wang Y, Garate M, Zhou J and Li G: The tumor suppressor ING3 is degraded by SCF(Skp2)-mediated ubiquitin-proteasome system. Oncogene 29: 1498-1508, 2010.

46. Tallen G and Riabowol K: Keep-ING balance: Tumor suppression by epigenetic regulation. FEBS Lett 588: 2728-2742, 2014.

47. Roe JS, Hwang CI, Somerville TDD, Milazzo JP, Lee EJ, Da Silva B, Maiorino L, Tiriac H, Young CM, Miyabayashi K, et al: Enhancer reprogramming promotes pancreatic cancer metastasis. Cell 170: 875-888.e20, 2017.

48. Weissmueller S, Manchado E, Saborowski M, Morris JP VI, WagenblastE, Davis CA, Moon SH,Pfister NT, Tschaharganeh DF, Kitzing T, et al: Mutant p53 drives pancreatic cancer metastasis through cell-autonomous PDGF receptor $\beta$ signaling. Cell 157: 382-394, 2014.

49. Santen RJ, Veldhuis J, Samojlik E, Lipton A, Harvey H and Wells SA: Mechanism of action of aminoglutethimide in breast cancer. Lancet 1: 44-45, 1979.

50. Li J, Cheng D, Zhu M, Yu H, Pan Z, Liu L, Geng Q, Pan H, Yan M and Yao M: OTUB2 stabilizes U2AF2 to promote the Warburg effect and tumorigenesis via the AKT/mTOR signaling pathway in non-small cell lung cancer. Theranostics 9: 179-195, 2019.

51. Wu X, Zhou Z, Xu S, Liao C, Chen X, Li B, Peng J, Li D and Yang L: Extracellular vesicle packaged LMP1-activated fibroblasts promote tumor progression via autophagy and stroma-tumor metabolism coupling. Cancer Lett 478: 93-106, 2020. 